periods reinforcing the need for suitable longer-term intensively staffed facilities in the community.

There was a sustained reduction in admissions but the gains appeared to plateau after the initial 2 years raising questions about the ongoing value of assertive outreach teams. As originally conceived, the teams' intervention was intended to be indefinite and the argument made that gains would be lost once the service was withdrawn. However, this position has become increasingly contentious. Indeed, the philosophy of 'no discharge' may be to the detriment of both individuals and services. ${ }^{5}$ In this study only one person left and then returned to an assertive outreach team, whereas admission rates were lowest for people transferred to other teams. Although indicating that people can do well on moving to less intensive services, this may have been anticipated given the people's perceived suitability for transfer. However, it is possible, given the plateau effect seen here after the first 2 years, that turnover of people on assertive outreach case-loads is too low (less than $5 \%$ per year here) and suggests that teams need to give more emphasis to exit strategies and set targets for moving on. ${ }^{5}$

\section{About the authors}

Tanvir Rana is a consultant psychiatrist at the South Staffordshire and Shropshire Healthcare NHS Foundation Trust, Stafford, and Martin Commander is a consultant psychiatrist at Birmingham and Solihull Mental Health Trust, Northcroft, Birmingham

\section{References}

1 Department of Health. The Mental Health Policy Implementation Guide. Department of Health, 2001.

2 Killaspy H. Assertive community treatment in psychiatry. BMJ 2007; 335: 311-2.

3 Commander M, Sashidharan S, Rana T, Ratnayake T. North Birmingham assertive outreach evaluation. Patient characteristics and clinical outcomes. Soc Psychiatry Psychiatr Epidemiol 2005; 40: 988-93.

4 Killaspy $\mathrm{H}$, Bebbington $\mathrm{P}$, Blizard $\mathrm{R}$, Johnson $\mathrm{S}$, Nolan $\mathrm{F}$, Pilling $\mathrm{S}$, et al. The REACT study: randomised evaluation of assertive community treatment in north London. BMJ 2006; 332: 815-8.

5 Burns T, Firn M. Assertive Outreach in Mental Health - A Manual for Practitioners. Oxford University Press, 2002.

6 Priebe S. Institutionalisation revisted - with and without walls. Acto Psychiatr Scand 2004; 110: 81-2.

\title{
Improving physical health monitoring for out-patients on antipsychotic medication
}

\author{
Carlos Gonzalez, Niyaz Ahammed, ${ }^{2}$ Robert Fisher $^{3}$
}

The Psychiatrist (2010), 34, 91-94, doi: 10.1192/pb.bp.108.021212

${ }^{1}$ East London NHS Foundation Trust: ${ }^{2}$ Oxleas NHS Foundation Trust; ${ }^{3}$ East London NHS Foundation Trust, St Bartholomew's Hospital

Correspondence to Robert Fisher (robert.fisher@eastlondon.nhs.uk)

\begin{abstract}
Aims and method Mental illness is associated with increased physical morbidity. We aimed to assess and improve the routine blood testing of prescribed antipsychotics in out-patients from a busy London inner city area. Audit findings were presented locally to prescribers, together with educational suggestions to improve physical health assessment.
\end{abstract}

Results Initially, the numbers monitored were low in the overall number of 126 patients included in the first audit. Following the intervention, this improved significantly in the second audit (of 106 patients).

Clinical implications A simple one-page monitoring prompt and an educational intervention could significantly increase the adherence to routine blood-testing guidelines. Better physical screening may help reduce physical morbidity and mortality, and improve the quality of life of individuals with mental illness.

Declaration of interest None.
Individuals with mental illness have markedly elevated rates of metabolic disturbance including obesity, diabetes and dyslipidaemia. ${ }^{1}$ In particular, individuals with schizophrenia have a $20 \%$ shorter life expectancy than the population at large. ${ }^{2}$ They have an increased relative risk of premature death, dying at least 10 years earlier than agematched individuals. ${ }^{3}$ This excess mortality has been largely attributed to 'natural causes' rather than suicide, ${ }^{3}$ but the health needs of people with schizophrenia who take antipsychotic medication are often not adequately addressed by clinicians, either in specialty mental health programmes or in primary care settings. ${ }^{2}$ The lack of consensus regarding which health parameters should be monitored has been a major obstacle to improving physical health monitoring, an issue that was addressed at the Mount Sinai Conference in New York. $^{2}$ 
In the UK, an expert consensus meeting ${ }^{4}$ described the association between schizophrenia, antipsychotics and diabetes, and drew up recommendations for screening and management. Subsequent local audits in rural areas ${ }^{5,6}$ have shown that out-patients are much less likely to have blood tests and physical health screening than in-patients (e.g. case vignette in the online supplement to this paper). A UK national audit ${ }^{7}$ of patients taking antipsychotics, under the care of 48 assertive outreach teams, found rates of screening for metabolic syndrome to be below those recommended; measurements of blood pressure, obesity, blood glucose and lipids were done in $26 \%, 17 \%, 28 \%$ and $22 \%$ of patients respectively. Although these patients are usually difficult to engage, they often receive intense input from assertive outreach teams. We therefore aimed to investigate physical monitoring in an out-patient context, where patients are less intensively supervised than in other settings with more resources such as in-patient services ${ }^{5,6}$ or assertive outreach teams. ${ }^{7}$

This study is based in a community mental health centre, serving a population of 70000 inhabitants, in an inner city London borough. The area has a high index of social deprivation and a large ethnic minority population. Most of the patients are monitored in out-patients' clinics, with no care coordinator.

\section{Method}

The data collection was carried out retrospectively by inspecting the patients' clinical records. A form of systematic randomisation was achieved by selecting every fourth file in alphabetical order, until $25 \%$ of the case-load had been selected, in the first audit. The selection of cases for the second audit followed the same method until an adequately sized matching sample was obtained. Only patients taking regular antipsychotics were included, excluding those on clozapine as they receive care through a specialist clinic where performance against standard is expected to be $100 \%$. A data collection tool was used to gather information on patient basic demographic data, diagnosis, antipsychotic medication, and baseline and continuation blood tests.

The standards were set by consensus by six local psychiatrists, using the recommendations of the American Diabetes Association ${ }^{8}$ and the Maudsley Prescribing Guidelines $2003^{9}$ and $2005 .^{10}$ It was agreed that all the patients prescribed antipsychotics should have a full blood count, urea and electrolytes, liver function tests, thyroid function tests, serum glucose and/or glycosylated haemoglobin (HblAc), serum prolactin, blood pressure and weight monitored at baseline and then again every 6 months.

The intervention included the presentation of data locally, three meetings with local consultants and two brief educational talks to junior doctors. A simple local adaptation of clinical guidelines was devised, and a monitoring tool was implemented (see online supplement). This tool was a simple A4 page filed in the patients' records, which was intended both as a prompt to doctors regarding their patients' need for the physical monitoring and as an instrument to facilitate later data collection.

Following this intervention, a re-audit was conducted in May 2006 to examine any change in practice. The data were again collected retrospectively over the previous year
(May 2005 to May 2006) and analysed using SPSS version 15 for Windows. Pearson $\chi^{2}$-test of independence was used to compare categorical variables. When more than $20 \%$ of cells had an expected value of less than 5 , a Fisher's exact test (two-sided) was performed; $P$ were corrected using the Bonferroni method to adjust for multiple comparisons.

\section{Results}

For the first audit, ${ }^{11}$ we included 126 patients treated with antipsychotics (except clozapine) between May 2004 and April 2005. This sample was obtained from 867 records which were randomly chosen from the total of 3466 case notes available as described before. The mean age was 42.43 years, with a standard deviation of 13.09 years. The majority of the sample were males (75 patients, 59.5\%), and predominantly White British (40 patients, $31.7 \%$ ), followed by Black African British (26 patients, 20.6\%). The main diagnosis was schizophrenia (56 patients, 44.4\%). Only 9 patients $(7.1 \%)$ were prescribed two antipsychotics in combination and the rest were on only one antipsychotic. ${ }^{11}$

For the second audit, 3967 case records had to be individually reviewed to obtain a sample of 106 patients. The mean age was 42.46 years with a standard deviation of 11.86 years. Again, the majority were male (59 patients, $55.7 \%$ ), White British (38 patients $35.8 \%$ ), Black African British (23 patients, 21.7\%), with a diagnosis of schizophrenia (54 patients, 50.9\%) and on antipsychotic monotherapy (100 patients, 94.3\%).

The two samples did not differ significantly in terms of age, gender, main ethnic categories, diagnosis, type and number of antipsychotics prescribed or route of administration. The monitoring of blood tests in each audit's cycle is compared in Table 1. Overall, there is a significant improvement $(P<0.001)$ in the performance of each test, except for HbAlc and prolactin. A more detailed comparison of the results according to the type of prescribed antipsychotic is presented in Tables 2 and 3 . The implementation of the monitoring tool was achieved in $48 \%$ of the re-audit sample.

\section{Discussion}

Overall performance against setting standards was initially poor; however, we managed to demonstrate a significant improvement following the re-audit for most of the tests. The only exceptions were prolactin and HbAlc levels, which may be explained by there being less clear recommendations in routine practice for these tests. In terms of the glycosylated haemoglobin, a random glucose level is regarded as a good screening test for diabetes, ${ }^{8}$ whereas HbAlc may be more valuable for actual monitoring of established diabetes, which should be part of treatment within primary care or a specialist diabetes service. ${ }^{4}$ With regard to prolactin, first-generation antipsychotics and risperidone are associated with hyperprolactinaemia, which may cause galactorrhoea, menstrual irregularities, sexual dysfunction and osteoporosis due to impairment in sex steroid production. ${ }^{2}$ Nevertheless, the recommendations from the Mount Sinai conference ${ }^{2}$ are that patients should have prolactin levels measured if clinically indicated (i.e. women presenting with breast milk secretion, changes in 


\begin{tabular}{|c|c|c|c|c|}
\hline & $\begin{array}{c}\text { First audit, } N=126 \\
n(\%)\end{array}$ & $\begin{array}{c}\text { Second audit, } N=106 \\
n(\%)\end{array}$ & $\chi^{2}$-test ${ }^{a}$ & $P^{\mathrm{b}}$ \\
\hline \multicolumn{5}{|l|}{ Baseline tests } \\
\hline $\mathrm{FBC}$ & $51(40.5)$ & $86(81.1)$ & 39.352 & $<0.001$ \\
\hline U\&E & 47 (37.3) & 80 (75.5) & 33.855 & $<0.001$ \\
\hline LFT & 49 (38.9) & $84(79.2)$ & 38.327 & $<0.001$ \\
\hline TFT & $38(30.4)$ & $76(71.7)$ & 39.138 & $<0.001$ \\
\hline Glucose & $31(24.6)$ & 77 (72.6) & 53.394 & $<0.001$ \\
\hline Lipids/cholesterol & $9(7.1)$ & $56(52.8)$ & 59.584 & $<0.001$ \\
\hline $\mathrm{HbA1c}$ & $4(3.2)$ & $6(5.7)$ & $0.862^{c}$ & $0.353^{c}$ \\
\hline Prolactin & $1(0.8)$ & $0(0)$ & $0.845^{c}$ & $0.358^{c}$ \\
\hline \multicolumn{5}{|l|}{ Continuation tests } \\
\hline FBC & $32(25.4)$ & $51(48.1)$ & 12.929 & $<0.001$ \\
\hline U\&E & $30(23.8)$ & $51(48.1)$ & 14.964 & $<0.001$ \\
\hline LFT & $31(24.6)$ & $51(48.1)$ & 13.924 & $<0.001$ \\
\hline TFT & $27(21.6)$ & $48(45.3)$ & 14.673 & $<0.001$ \\
\hline Glucose & $25(19.8)$ & $50(47.2)$ & 19.653 & $<0.001$ \\
\hline Lipids/cholesterol & $12(9.5)$ & $36(34.0)$ & 20.953 & $<0.001$ \\
\hline $\mathrm{HbA1c}$ & $4(3.2)$ & $6(5.7)$ & $0.862^{c}$ & $0.353^{c}$ \\
\hline Prolactin & $0(0)$ & $0(0)$ & $0.0^{c}$ & $0.0^{c}$ \\
\hline
\end{tabular}

FBC, full blood count; U\&E, urea and electrolytes; LFT, liver function test; TFT, thyroid function test; HbA1c, glycosylated haemoglobin. a. $\chi^{2}$-test of independence.

b. $P$ adjusted with the Bonferroni method for multiple comparisons.

c. For $\mathrm{HbA1c}$ (both baseline and continuation), $25 \%$ of cells have expected value of less than 5 , therefore a Fisher's exact test was done (two-sided $P=0.519$ ). For baseline prolactin, $50 \%$ of cells have expected value of less than 5 (Fisher's exact test, two-sided $P=1.00$ ). For continuation prolactin, no comparison test was performed as both audits have the same value (0).

menstruation or libido, and men presenting with changes in libido, erectile and ejaculatory function or galactorrhoea).

We did not include in this audit other important physical parameters for detection of the metabolic syndrome, such as blood pressure, pulse, and weight or body mass index, and neither did we include electrocardiogram (ECG) monitoring.

\section{Limitations}

One of the limitations of the study was that perhaps insufficient time was allowed between the intervention and the data collection for the second audit cycle. Thus continuation tests were perhaps less likely to be done due to an insufficient time lapse. It is also possible that improvement in monitoring was not related to our intervention, but rather a result of increased awareness within the service, due to local policy, national guidelines, ${ }^{12}$ or some other factor not accounted for. The restructuring of the trust was a significant obstacle for obtaining an adequate matching sample during the re-audit. Files were kept in two different locations, six community mental health teams were relocated and reformed into acute and

Table 2 Blood tests for patients taking second-generation antipsychotics

\begin{tabular}{|c|c|c|c|c|c|c|}
\hline & \multicolumn{2}{|c|}{ Olanzapine } & \multicolumn{2}{|c|}{ Risperidone } & \multicolumn{2}{|c|}{ Other atypicals ${ }^{a}$} \\
\hline & $\begin{array}{c}\text { First audit, } N=43 \\
n(\%)\end{array}$ & $\begin{array}{l}\text { Second audit, } \\
N=39, n(\%)\end{array}$ & $\begin{array}{c}\text { First audit, } N=28 \\
n(\%)\end{array}$ & $\begin{array}{l}\text { Second audit, } \\
N=23, n(\%)\end{array}$ & $\begin{array}{c}\text { First audit, } N=7 \\
n(\%)\end{array}$ & $\begin{array}{c}\text { Second audit, } \\
N=6, n(\%)\end{array}$ \\
\hline \multicolumn{7}{|l|}{ Baseline } \\
\hline $\mathrm{FBC}$ & $21(48.8)$ & 31 (79.5) & $9(32.1)$ & $20(87.0)$ & $4(57.1)$ & $5(83.3)$ \\
\hline U\&E & $19(44.2)$ & $28(71.8)$ & $8(28.6)$ & $20(87.0)$ & $4(57.1)$ & $3(50.0)$ \\
\hline LFT & $20(46.5)$ & $29(74.4)$ & $9(32.1)$ & 21 (91.3) & $4(57.1)$ & $5(83.3)$ \\
\hline TFT & 15 (34.9) & $26(66.7)$ & $3(10.7)$ & $18(78.3)$ & $3(42.9)$ & $5(83.3)$ \\
\hline Glucose & $13(30.2)$ & $29(74.4)$ & $4(14.3)$ & 18 (78.3) & $4(57.1)$ & $3(50.0)$ \\
\hline Lipids & $3(7.0)$ & 19 (48.7) & $2(7.1)$ & 13 (56.5) & $2(28.6)$ & $2(33.3)$ \\
\hline $\mathrm{HbA1c}$ & $1(2.3)$ & $1(2.6)$ & $0(0)$ & $1(4.3)$ & $0(0)$ & $1(16.7)$ \\
\hline Prolactin & $0(0)$ & $0(0)$ & $0(0)$ & $0(0)$ & $0(0)$ & $0(0)$ \\
\hline \multicolumn{7}{|l|}{ Continuation } \\
\hline $\mathrm{FBC}$ & 8 (18.6) & $18(46.2)$ & $7(25.0)$ & $12(52.2)$ & $4(57.1)$ & $4(66.7)$ \\
\hline U\&E & $7(16.3)$ & $18(46.2)$ & $7(25.0)$ & $12(52.2)$ & $4(57.1)$ & $3(50.0)$ \\
\hline LFT & 9 (20.9) & 17 (43.6) & $7(25.0)$ & $12(52.2)$ & $4(57.1)$ & $4(66.7)$ \\
\hline TFT & $7(16.3)$ & $16(41.0)$ & $5(17.9)$ & $12(52.2)$ & $4(57.1)$ & $4(66.7)$ \\
\hline Glucose & 7 (16.3) & 17 (43.6) & 5 (17.9) & $12(52.2)$ & $4(57.1)$ & $3(50.0)$ \\
\hline Lipids & $3(7.0)$ & $11(28.2)$ & $2(7.1)$ & 9 (39.1) & $3(42.9)$ & $2(33.3)$ \\
\hline $\mathrm{HbA1c}$ & $2(4.7)$ & $0(0)$ & $0(0)$ & $2(8.7)$ & $0(0)$ & $1(16.7)$ \\
\hline Prolactin & $0(0)$ & $0(0)$ & $0(0)$ & $0(0)$ & $0(0)$ & $0(0)$ \\
\hline
\end{tabular}

FBC, full blood count; U\&E, urea and electrolytes; LFT, liver function test; TFT, thyroid function test; HbA1c, glycosylated haemoglobin. a. Other atypicals include quetiapine, amisulpride and aripiprazole. 
Table 3 Blood tests for patients taking first-generation antipsychotics

\begin{tabular}{|c|c|c|c|c|c|c|}
\hline & \multicolumn{2}{|c|}{ Clopixol } & \multicolumn{2}{|c|}{ Depixol } & \multicolumn{2}{|c|}{ Other typicals ${ }^{a}$} \\
\hline & $\begin{array}{c}\text { First audit, } N=11 \\
n(\%)\end{array}$ & $\begin{array}{l}\text { Second audit, } \\
N=5, n(\%)\end{array}$ & $\begin{array}{c}\text { First audit, } N=18 \\
n(\%)\end{array}$ & $\begin{array}{l}\text { Second audit, } \\
N=13, n(\%)\end{array}$ & $\begin{array}{c}\text { First audit, } N=28 \\
n(\%)\end{array}$ & $\begin{array}{l}\text { Second audit, } \\
N=23, n(\%)\end{array}$ \\
\hline \multicolumn{7}{|l|}{ Baseline } \\
\hline $\mathrm{FBC}$ & $4(36.4)$ & $3(60.0)$ & $8(44.4)$ & $10(76.9)$ & $11(39.3)$ & $19(82.6)$ \\
\hline U\&E & $3(27.3)$ & $3(60.0)$ & $8(44.4)$ & $10(76.9)$ & $11(39.3)$ & $18(78.3)$ \\
\hline LFT & $3(27.3)$ & $3(60.0)$ & $8(44.4)$ & $10(76.9)$ & $11(39.3)$ & $18(78.3)$ \\
\hline TFT & $4(36.4)$ & $3(60.0)$ & $7(38.9)$ & $8(61.5)$ & $11(39.3)$ & $19(82.6)$ \\
\hline Glucose & $3(27.3)$ & $3(60.0)$ & $6(33.3)$ & $10(76.9)$ & $5(17.9)$ & $16(69.6)$ \\
\hline Lipids & $1(9.1)$ & $3(60.0)$ & $0(0)$ & $5(38.5)$ & $2(7.1)$ & $15(65.2)$ \\
\hline $\mathrm{HbA1c}$ & $0(0)$ & $0(0)$ & $2(11.1)$ & $1(7.7)$ & $2(7.1)$ & $2(8.7)$ \\
\hline Prolactin & $1(9.1)$ & $0(0)$ & $0(0)$ & $0(0)$ & $0(0)$ & $0(0)$ \\
\hline \multicolumn{7}{|l|}{ Continuation } \\
\hline $\mathrm{FBC}$ & $3(27.3)$ & $1(20.0)$ & $7(38.9)$ & $6(46.2)$ & $7(25.0)$ & $13(56.5)$ \\
\hline U\&E & $3(27.3)$ & $1(20.0)$ & 7 (38.9) & $6(46.2)$ & $5(17.9)$ & $14(60.9)$ \\
\hline LFT & $2(18.2)$ & $1(20.0)$ & $7(38.9)$ & $6(46.2)$ & $6(21.4)$ & $14(60.9)$ \\
\hline TFT & $3(27.3)$ & $1(20.0)$ & $6(33.3)$ & $5(38.5)$ & $5(17.9)$ & $13(56.5)$ \\
\hline Glucose & $4(36.4)$ & $1(20.0)$ & $4(22.2)$ & $6(46.2)$ & $5(17.9)$ & $14(60.9)$ \\
\hline Lipids & $1(9.1)$ & $1(20.0)$ & $2(11.1)$ & $3(23.1)$ & $3(10.7)$ & $11(47.8)$ \\
\hline $\mathrm{HbA1c}$ & $0(0)$ & $0(0)$ & $1(5.6)$ & $1(7.7)$ & $2(7.1)$ & $2(8.7)$ \\
\hline Prolactin & $0(0)$ & $0(0)$ & $0(0)$ & $0(0)$ & $0(0)$ & $0(0)$ \\
\hline
\end{tabular}

FBC, full blood count; U\&E, urea and electrolytes; LFT, liver function test; TFT, thyroid function test; HbA1c, glycosylated haemoglobin. a. Other typicals include haloperidol, stelazine, modecate, sulpiride and pirpoptil.

long-term care, meaning that for the second audit, 3967 case records had to be individually reviewed to obtain a second sample of 106 patients. Another pitfall was the withdrawal of one consultant from their commitment to the audit implementation project.

Our suggestions for improving physical monitoring in psychiatric out-patient settings include the regular audit of current practice within the service, the incorporation of some prompting and monitoring tool within the clinical notes, adequate training of team members (especially doctors) as part of their educational programmes, adequate reporting systems and communication with primary care, and periodical reviews of an agreed protocol within the service, allowing for pharmacist and consultant involvement.

Key barriers to the implementation of physical health monitoring in psychiatric settings include unclear responsibilities, competing demands on limited resources, and liability issues. ${ }^{1}$ There is a debate, for example, about whether responsibility lies within primary or secondary care, thus Cohn \& Sernyak suggest that it is not necessary for psychiatrists actually to perform a specific task, even though they are responsible for ensuring that the task is clearly delegated. ${ }^{1}$ Some prescribers may be also concerned about a lack of expertise in interpreting the results or an inadequate response to positive screenings. This concern is legitimate, and should be addressed through education and planning. The alternative - no monitoring - is clearly unacceptable.

\section{Acknowledgements}

We thank Carol Paton for invaluable advice on an earlier version of this article, and Dr Nandani Thavapalan, Dr Michael Cozzolino, Dr Saqib Latif, Dr Bogdan Banjac and Marian Reardon for all their help in the execution of the audits.

\section{About the authors}

Carlos Gonzalez is Specialty Registrar, East London NHS Foundation Trust Niyaz Ahammed is Senior House Officer, Oxleas NHS Foundation Trust. Robert Fisher is Consultant Psychiatrist, East London NHS Foundation Trust, Department of Psychological Medicine, St Bartholomew's Hospital, London.

\section{References}

1 Cohn TA, Sernyak MJ. Metabolic monitoring for patients treated with antipsychotic medications. Can J Psychiatry 2006; 51: 492-501.

2 Marder SR, Essock SM, Miller AL, Buchanan RW, Casey DE, Davis JM, et al. Physical health monitoring of people with schizophrenia. Am J Psychiatry 2004; 161: 1334-49.

3 Brown S. Excess mortality of schizophrenia. A meta-analysis. $\mathrm{Br} \mathrm{J}$ Psychiatry 1997; 171: 502-8.

4 Expert Group. 'Schizophrenia and Diabetes 2003' Expert Consensus Meeting, Dublin, 3-4 October 2003: consensus summary. $\mathrm{Br} \mathrm{J}$ Psychiatry 2004; 184: s112-4

5 Tarrant CJ. Blood glucose testing for adults prescribed atypical antipsychotics in primary and secondary care. Psychiatr Bull 2006; 30: 286-8.

6 Feeney L, Mooney M. Atypical antipsychotic monitoring in the Kilkenny Mental Health Services. Ir J Psych Med 2005; 22: 101-2.

7 Barnes TR, Paton C, Cavanagh MR, Hancock E, Taylor DM. A UK audit of screening for the metabolic side effects of antipsychotics in community patients. Schizophr Bull 2007; 33: 1397-403.

8 American Diabetes Association. Screening for type 2 diabetes. Diabetes Care 2004; 27: s11-4.

9 Taylor D, Paton C, Kerwin R. The Maudsley 2003 Prescribing Guidelines (7th edn). Martin Dunitz, 2003.

10 Taylor D, Paton C, Kerwin R. The Maudsley Prescribing Guidelines 20052006 (8th edn). Taylor \& Francis Group, 2005.

11 Fisher R. Monitoring of antipsychotic prescriptions in an inner city district of London [in German]. Nervenarzt 2006; 77 (suppl 3): s140.

12 National Institute for Clinical Excellence. Schizophrenia: Full National Clinic Guidelines on Core Interventions in Primary and Secondary Care. Royal College of Psychiatrists \& The British Psychological Society, 2003. 